\title{
A Novel Quad-band Printed Antenna Design using a Multi-Slotted Patch for Cellular Communication
}

\author{
P. Misra \\ Eastern Academy of Sc \& Tech \\ BBSR \\ INDIA
}

\author{
A. Tripathy \\ Eastern Academy of Sc \& Tech \\ BBSR \\ INDIA
}

\begin{abstract}
This article proposes a quad band patch antenna for mobile communication. The design requirements are to meet the 0.9 $\mathrm{GHz}, 1.8 \mathrm{GHz}, 2.1 \mathrm{GHz}$ and $2.45 \mathrm{GHz}$ bands. The proposed antenna consists of a rectangular patch monopole printed antenna in which slotting technique is used to achieve multi band resonance. The Patch with three slotted lines generates four resonating frequencies to cover $0.9 \mathrm{GHz}$ GSM band, 1.8 $\mathrm{GHz}$ DCS band, $2.1 \mathrm{GHz} 3 \mathrm{G}$ band and $2.45 \mathrm{GHz}$ ISM band. Slots are optimized to achieve proper quad band operation of the antenna. The proposed antenna is fed by using a $50 \mathrm{ohm}$ microstrip line. The simulated results in terms of return loss, VSWR $(<2)$ indicate the suitability of the antenna for mobile communication. The designed antenna is simulated using CST Microwave studio.
\end{abstract}

\section{Keywords}

Quad band, monopole, patch, slots and stripes

\section{INTRODUCTION}

Printed antennas are becoming very popular for the design requirement, especially in terms of their low profile, wide bandwidth, ease to integrate with radio circuitry and simple to mount on printed circuit board. Printed monopole antenna are mostly fed by a microstrip feed network. Various patch shapes like circular disk, square and rectangular have been examined in literature [1-5]. The ground plane plays as an important role for the monopole antenna design process, in which its size against the bandwidth achieved at antenna input port is the most crucial part [6]. PIFA determines the number of resonant modes and also the ground plane dimensions determine bandwidth, effectively at the lower frequencies [7-8]. Most of the work has been done on antenna design but the ground plane both its dimensions and its modification [9] offers another design variable. Compact multi band antennas for wireless communication are reported [10-13]. This paper presents a quad band antenna-design where slots and strips are used to obtain the multiband operation. The whole antenna structure covers a volume of $77 \mathrm{~mm} \times 36 \mathrm{~mm} \times 1.6 \mathrm{~mm}$. The antenna is fed by a microstrip line of width $3 \mathrm{~mm}$ with an input impedance of $50 \Omega$. The proposed antenna is simple to design and offer an effective control of four operating bands by controlling the dimensions of three slots on patch. The antenna geometry and design theory are described in the following sections. The current distribution, radiation pattern are also discussed in the following sections.

\section{ANTENNA DESIGN}

The proposed quad band antenna is designed using FR4 substrate with a dielectric constant 4.4 of height $1.6 \mathrm{~mm}$. The total volume of the designed structure is defined by the substrate i.e. $77 \mathrm{~mm} \times 36 \mathrm{~mm} \times 1.6 \mathrm{~mm}$. The design uses a patch with three slotting arms on it and fed by microstrip line of width $3 \mathrm{~mm}$. The geometry is determined in three steps by inserting narrow slots on it. The design is started with the lower bands then the higher modes are investigated.

\subsection{Design at lower resonant mode}

The patch with a dimension of $21 \mathrm{~mm} \times 36 \mathrm{~mm}$ is used for the lower mode i.e. for $0.9 \mathrm{GHz}$ band. The feed line is varied from $40 \mathrm{~mm}$ to $55 \mathrm{~mm}$ to meet the resonant mode and is fixed at $55 \mathrm{~mm}$ with a ground plane of dimension $7 \mathrm{~mm} \times 36 \mathrm{~mm}$. The designed structure for lower resonant mode and its simulated return loss plot are shown in fig 1 and 2 respectively.

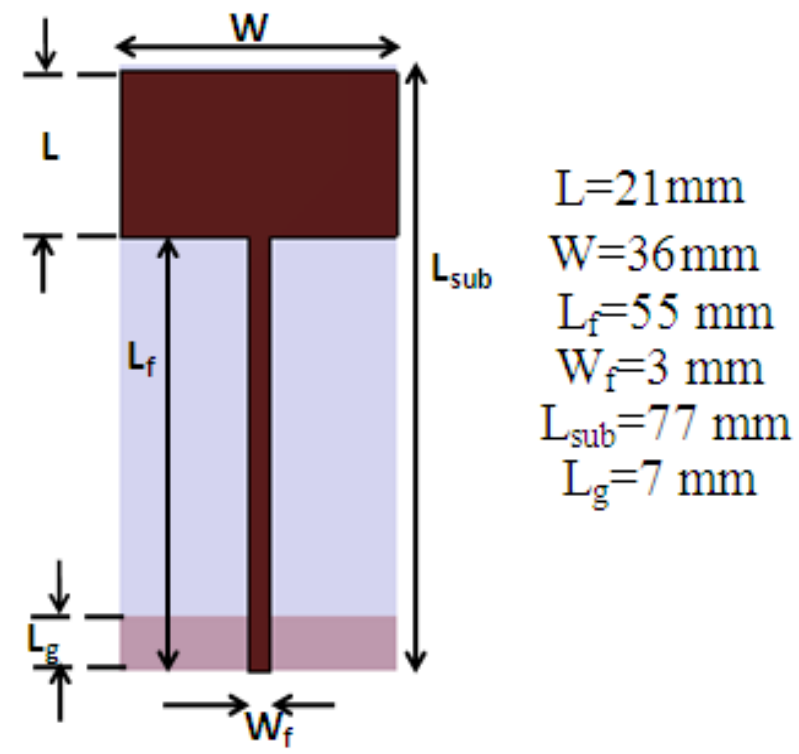

Fig 1: Antenna geometry for lower band $(0.9 \mathrm{GHz})$

The antenna geometry having the dimension of its parameters is shown in fig 1 . The simulated result in terms of return loss and VSWR plot has been given in fig 2 . 

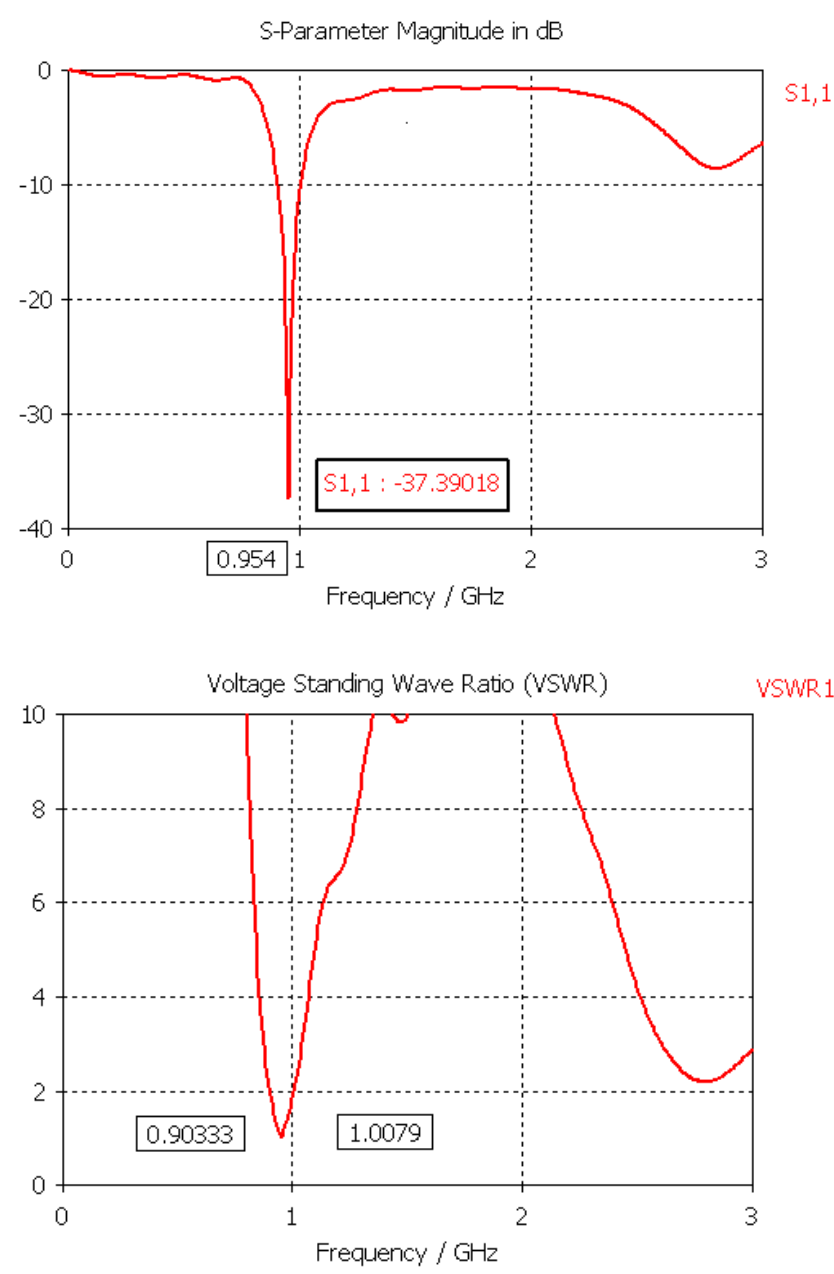

Fig 2: Simulated return loss and VSWR plot

The antenna resonates at $0.954 \mathrm{GHz}$ with a good return loss of $37.384 \mathrm{~dB}$. The bandwidth (VSWR>2) is from 0.903-1.007 GHz. Now the slotting techniques are introduced to create the higher modes of resonance.

\subsection{Creation of additional resonant modes}

The length and width of patch are useful parameters for determining the resonant modes. Here using slots on the radiator the desired resonant modes are investigated. Variation of slot dimension and position is studied to achieve the new resonant modes at the higher frequencies. The $\mathrm{L}$ shaped slot turns the frequency response of the antenna to a dual band resonant mode. The $\mathrm{L}$ slot is completely responsible for the $1.8 \mathrm{GHz}$ band. The only horizontal section of $\mathrm{L}$ slot creates the $1.8 \mathrm{GHz}$ band and the vertical slot is for achieving impedance matching which results a more negative return loss. The next two horizontal slots are responsible for the 2.1 $\mathrm{GHz}$ band and $2.45 \mathrm{GHz}$ band. The lengths of the slots are tuned to optimize the structure with desired multiband frequency. Position of horizontal slots in the upward direction meets the higher frequencies with maintaining lower modes and makes the antenna suitable for multiband operation. The detail geometry of the designed antenna for quad band operation is shown in fig 3 and the dimensions of the designed antenna parameters are also given. The simulated return loss plots with different slots are shown in fig 4 then the current distributions on the radiator are studied with the corresponding resonant modes.
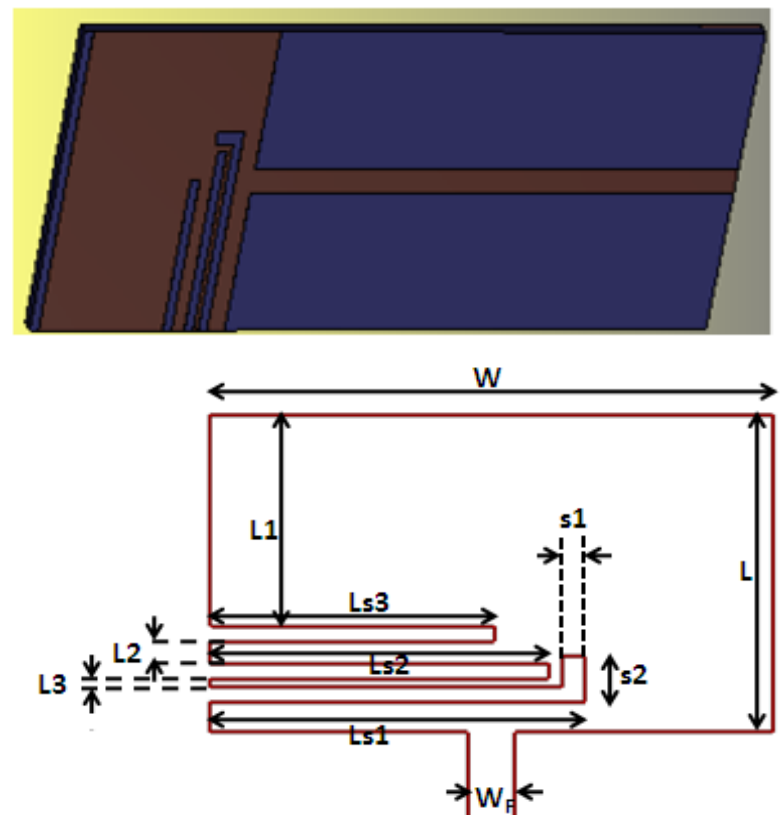

$\left(\mathrm{L}=21 \mathrm{~mm}, \mathrm{~W}=\mathrm{Wg}=36 \mathrm{~mm}, \mathrm{~W}_{\mathrm{f}}=3 \mathrm{~mm}, \mathrm{~L}_{\mathrm{f}}=55 \mathrm{~mm}, \mathrm{Lg}=7\right.$ $\mathrm{mm}, \mathrm{Lsub}=77 \mathrm{~mm}, \mathrm{~L} 1=14 \mathrm{~mm}, \mathrm{~L} 2=1.45 \mathrm{~mm}, \mathrm{~L} 3=0.55$ $\mathrm{mm}, \mathrm{Ls} 1=24 \mathrm{~mm}, \mathrm{Ls} 2=21.65 \mathrm{~mm}, \mathrm{Ls} 3=18.2 \mathrm{~mm}, \mathrm{~s} 1=1.5$ $\mathrm{mm}, \mathrm{s} 2=3 \mathrm{~mm}$ )

Fig 3: Proposed quad band antenna structure
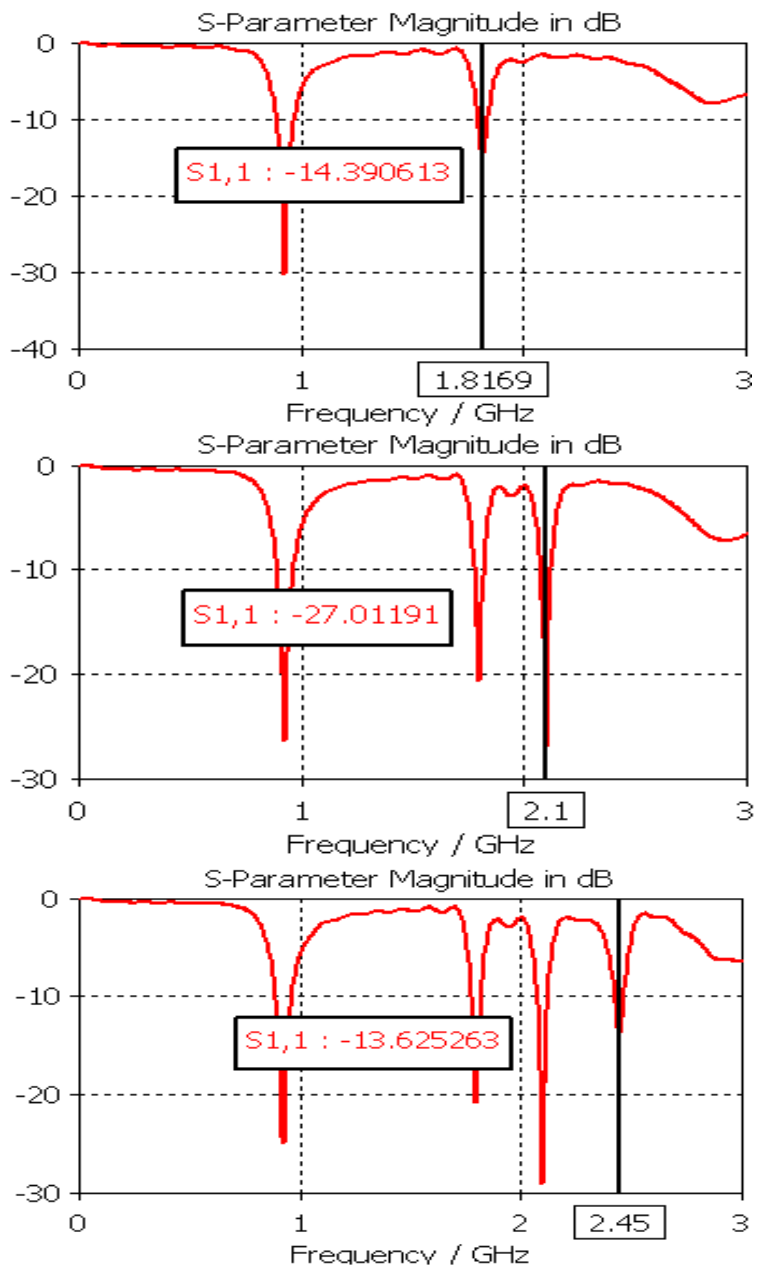

Fig 4: Simulated return loss plots with $L$ slot at bottom, horizontal slot at middle and horizontal slot at top 
The designed antenna is simulated in the frequency range 0- 3 $\mathrm{GHz}$ and the results in terms of return loss and VSWR are shown in fig 5 .
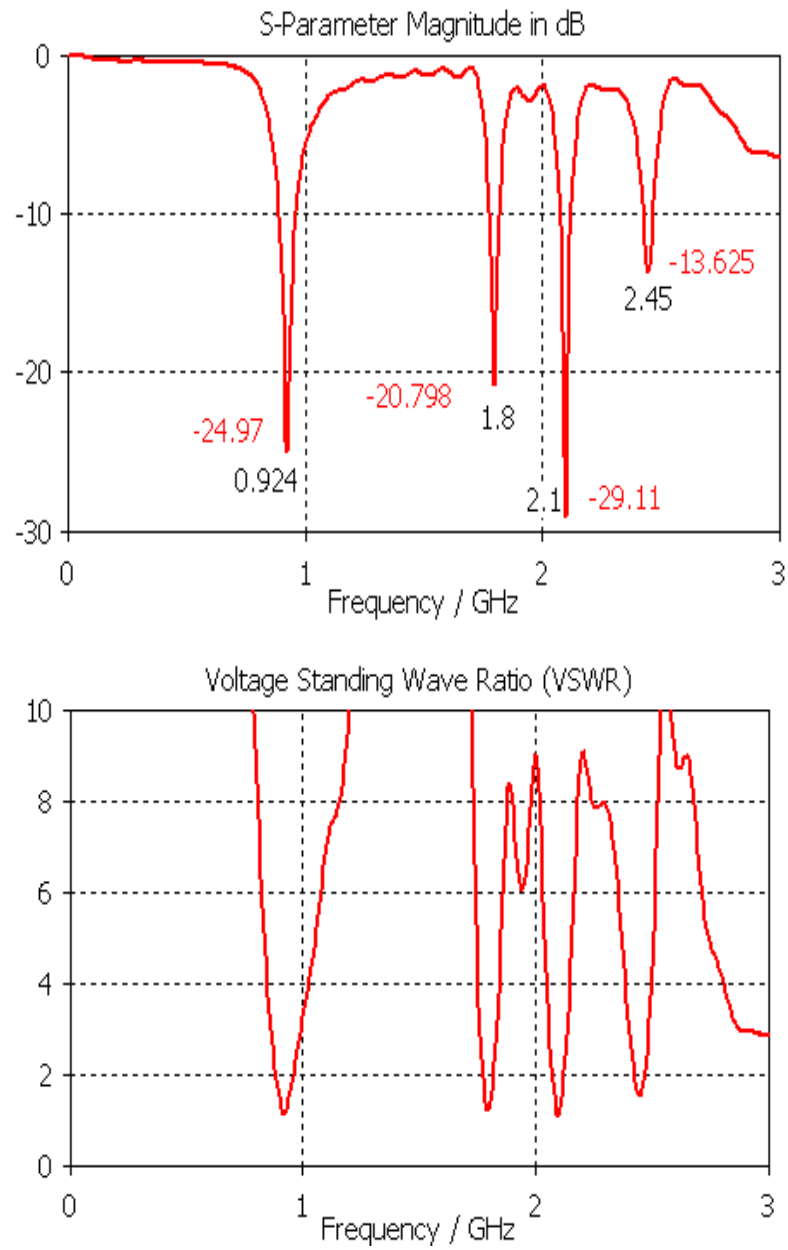

Fig 5: Simulated return loss and VSWR plot

The return loss plot meets the required bands with good return loss. Also it is observed from the VSWR plot which satisfies good agreement for the resonant frequencies. The return loss and VSWR for the resonant frequencies are given in table 1.

Table 1. Frequency properties

\begin{tabular}{|c|c|c|c|}
\hline $\begin{array}{c}\text { Resonant } \\
\text { frequency } \\
\text { in GHz }\end{array}$ & $\begin{array}{c}\text { RL in } \\
\text { dB }\end{array}$ & $\begin{array}{c}\text { VSWR } \\
(\mathbf{m i n})\end{array}$ & $\begin{array}{c}\text { BW (VSWR } \\
\text { below 2) in GHz }\end{array}$ \\
\hline 0.924 & -24.97 & 1.11 & $0.8852-0.9616$ \\
\hline 1.8 & -20.798 & 1.2 & $1.775-1.819$ \\
\hline 2.1 & -29.11 & 1.07 & $2.072-2.123$ \\
\hline 2.45 & -13.625 & 1.5 & $2.425-2.470$ \\
\hline
\end{tabular}

\section{CURRENT DISTRIBUTION}

The physical behavior of the antenna is analyzed from the current distribution pattern. In simulation, antennas with different slot dimensions on patch are investigated for multiband characteristics. The current distribution pattern on the radiator provides a good agreement for the resonant mode corresponding to the slot position and dimension. The surface current distributions at $0.924 \mathrm{GHz}, 1.8 \mathrm{GHz}, 2.1 \mathrm{GHz}$ and $2.45 \mathrm{GHz}$ are studied which are given in fig 6 below.
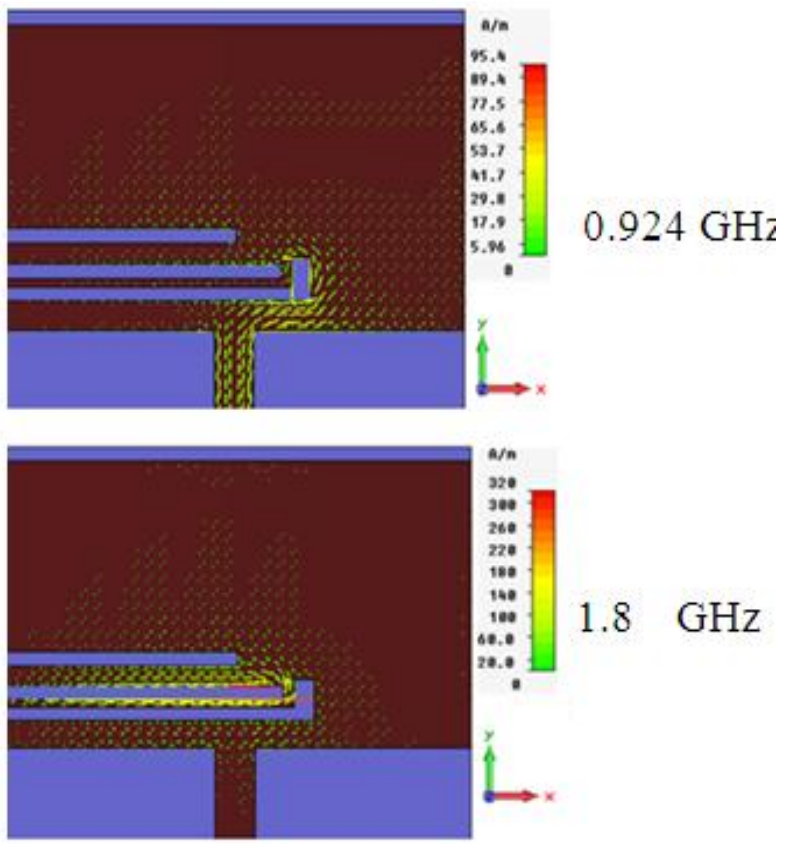

\section{$1.8 \mathrm{GHz}$}

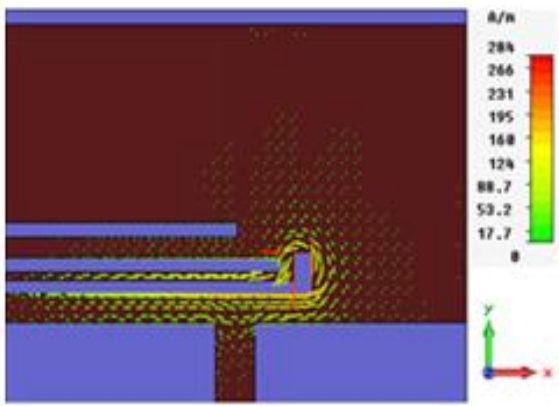

\section{$2.1 \mathrm{GHz}$}

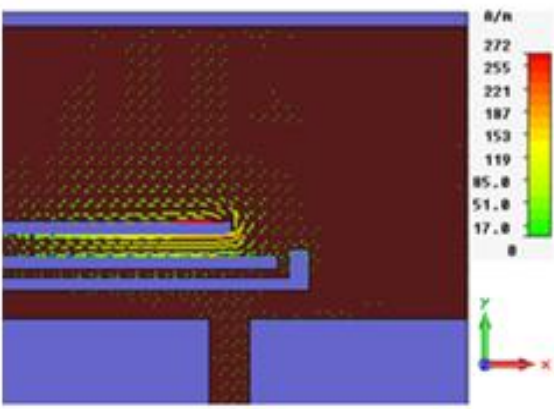

$2.45 \mathrm{GHz}$

Fig 6: Surface current distribution at resonant frequencies

From fig 6 it is observed that the surface current distribution at different frequencies is associated with the particular antenna configuration generated using slots for that resonant mode. The initial design for the lower mode is for $0.9 \mathrm{GHz}$ band, The $\mathrm{L}$ slot covering radiator is denser with surface current distribution at the $1.8 \mathrm{GHz}$. The other two horizontal slots also provide good agreement of current distribution on the patch for the corresponding resonant modes. The middle slot just above the $\mathrm{L}$ slot satisfies the $2.1 \mathrm{GHz}$ where surface current distribution on the patch is observed around the slot and the top most horizontal slot on patch is for $2.45 \mathrm{GHz}$ band. 


\section{RADIATION PATTERNS}

The far field radiation patterns in terms of 3D view and polar plot for the proposed quad band antenna are shown in fig 7
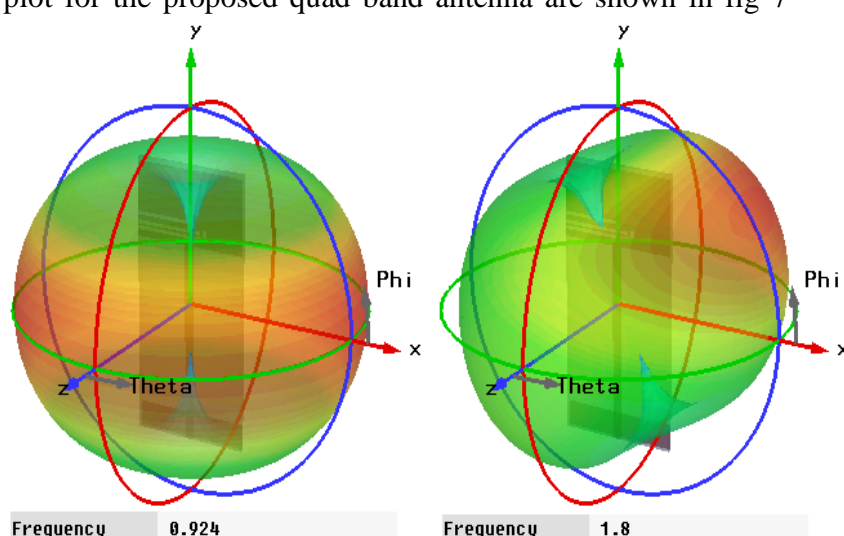

Frequenc and 8 at the resonant frequencies $0.924 \mathrm{GHz}, 1.8 \mathrm{GHz}, 2.1$ $\mathrm{GHz}$ and $2.45 \mathrm{GHz}$ respectively.

Fig 7: 3D Radiation patterns

Farfield 'farfield [f=0.924] [1]' Directivity Abs[Theta]

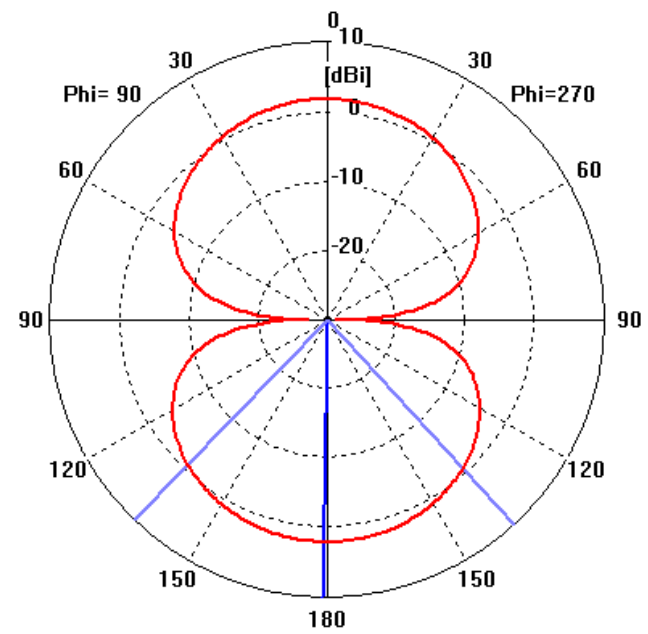

Farfield 'farfield $[f=2.1][1]$ ' Directivity_Abs[Theta]

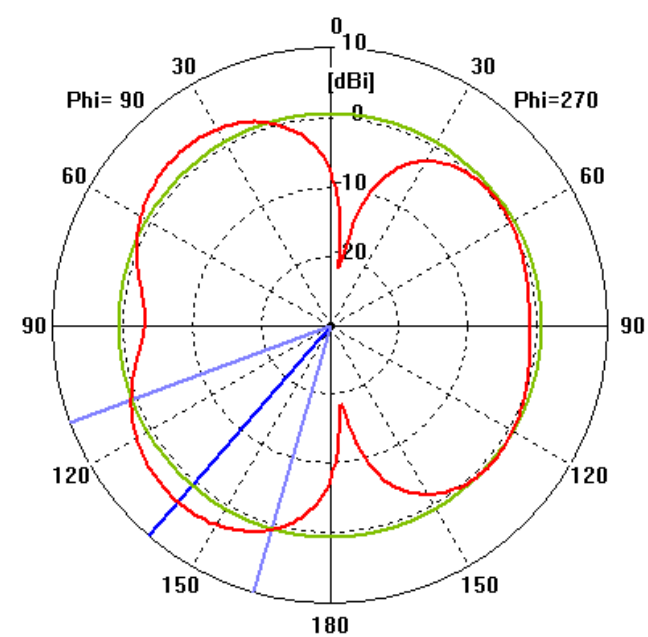

Farfield 'farfield [f=1.8] [1]' Directivity_Abs[Theta]

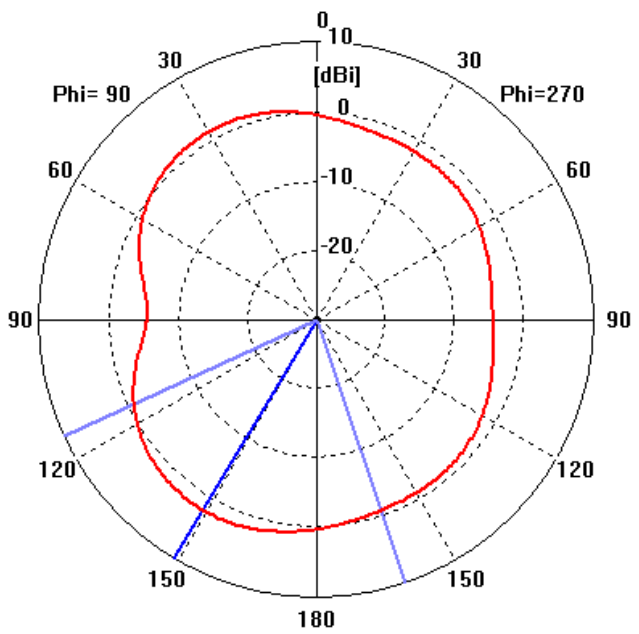

Farfield 'farfield [ $f=2.45]$ [1]' Directivity_Abs[Theta]

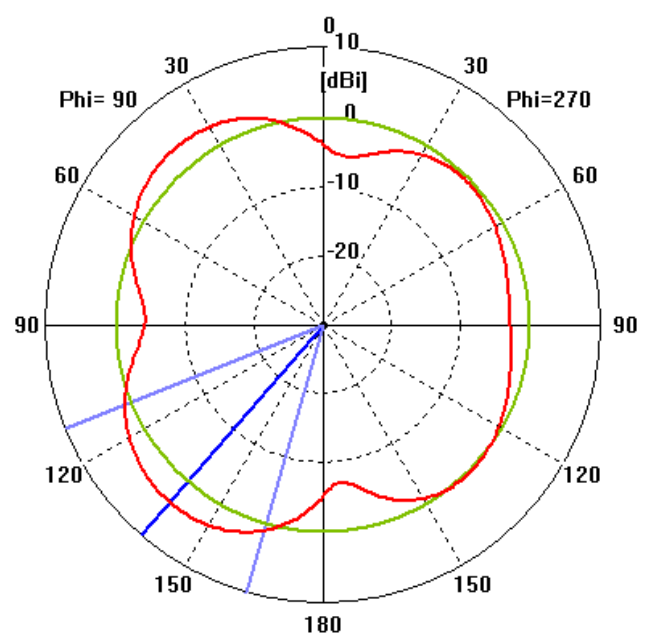

Fig 8: Radiation patterns (polar plot) 


\section{CONCLUSION}

The designed antenna satisfies quad band operation. Also the antenna is compact in size which can be suitable for integration with the packaging device. In this paper, the multiband configuration of the antenna is achieved by controlling the three slotting arms on the patch. The antenna resonates at $0.9 \mathrm{GHz}(\mathrm{GSM}) 1.8 \mathrm{GHz}(\mathrm{DCS}), 2.1 \mathrm{GHz}(3 \mathrm{G})$ and $2.45 \mathrm{GHz}$ (ISM) with good return loss and VSWR $(<2)$ which can be suitable for cellular communication applications.

\section{REFERENCES}

[1] Sadat, S., M. Fardis, F. Geran, and G. Dadashzadeh, "A compact microstrip square-ring slot antenna for UWB applications," Progress In Electromagnetics Research, PIER 67, 173-179, 2007.

[2] C.-T. Lee and K.-L. Wong, "Uniplanar Printed CoupledFed PIFA With a Band-Notching Slit for WLAN/WiMax Operation in the Laptop Computer", IEEE Trans. Antennas and Propagation, vol.57, April 2009, pp.12521258 .

[3] D. Liu and B. Gaucher, "A new Multiband Antenna for WLAN/Cellular Applications", IEEE Vehicular Technology Society Conference, Milan, Vol.1, Sept.2004, pp.243-246

[4] H.-C. Tung, S.T. Fang and K.L Wong, "Printed DualBand Monopole Antenna for $2.4 / 5.2 \mathrm{GHz}$ WLAN Access Point", Microwave and Optical Technology Letters, vol.35, no.4, Nov. 2002, pp.286-288.

[5] D.D. Krishna, M. Gopikrishna, C.K. Anandan, P. Mohanan and K. Vasudevan, "CPW-Fed Koch Fractal Slot Antenna for WLAN/WiMax Applications". IEEE Antennas and Wireless Propagation Letters, Vol.7, pp.389-392, 2008.

[6] K. P. Ray, Y. Ranga, and P. Gabhale, "Printed square monopole antenna with semicircular base for ultra-wide bandwidth," Electronics Letters, vol. 43, no. 5, 263 pages, 2007.

[7] Tae-Hyun Kim and Dong-Chul Park, Compact DualBand Antenna with Double L-Slits for WLAN Operation, IEEE Antennas and Wireless Propagation Letters, VOL. 4, 2005.

[8] T. Y. Wu and K. L. Wong, "On the impedance bandwidth of a planar inverted-F antenna for mobile handsets," Microw. Opt. Tech. Lett., vol. 32, pp. 249251, Feb. 2002

[9] M. C. Huynh and W. Stutzman, "Ground plane effects on planar inverted-F antenna (PIFA) performance," Proc. Inst. Elect. Eng. Microw. Antennas Propag, vol. 150, no. 4, Aug. 2003

[10] A. Byndas, R. Hossa, M. E. Bialkowski, and P. Kabacik, "Investigations into operation of single multi-layer configuration of planar inverted- $\mathrm{F}$ antenna," IEEE Antennas Propag. Mag., vol. 49, no. 4, pp. 22-33, Aug. 2007.

[11] Qinjiang Rao and Tayeb A. Denidni, New Broadband Dual- Printed Inverted L - Shaped Monopole Antenna for Tri-band Wireless Applications, Microwave and Optical Technology letters, vol.49, no.2, pp.278-280, Feb. 2007.

[12] Li-Na Zhang, Shun-Shi Zhong, Xian-Ling Liang and Chun-Hui Li, Compact Meander Monopole Antenna for Tri-band WLAN Applications, Microwave and Optical Technology letters, vol.49, no.4, pp.986-988, April 2007.

[13] Yue Song, Yong-Chang Jiao, Hui Zhao, Zheng Zhang, Zi-Bin Weng, and Fu-Shun Zhang, Compact Printed Monopole Antenna for Multiband WLAN Applications, Microwave and Optical Technology letters, vol.50, no.2, pp.365-367, Feb. 2008. 